\title{
Biomechanical Evaluation of 3 Stabilization Methods on Acromioclavicular Joint Dislocations
}

\author{
Jakob V. Nüchtern, ${ }^{\star \dagger}$ MD, Kay Sellenschloh, ${ }^{\ddagger}$ Nick Bishop, ${ }^{\ddagger}$ Sabrina Jauch, ${ }^{\ddagger}$ \\ Daniel Briem, ${ }^{\dagger} \mathrm{MD}$, Michael Hoffmann, ${ }^{\dagger} \mathrm{MD}$, Wolfgang Lehmann, ${ }^{\dagger} \mathrm{MD}$, Klaus Pueschel, ${ }^{\S} \mathrm{MD}$, \\ Michael M. Morlock, ${ }^{\ddagger} \mathrm{PhD}$, Johannes M. Rueger, ${ }^{\dagger} \mathrm{MD}$, and Lars G. Großterlinden, ${ }^{\dagger} \mathrm{MD}$ \\ Investigation performed at the Biomechanics Section, Hamburg University of Technology, \\ Hamburg, Germany
}

Background: Traumatic acromioclavicular (AC) joint dislocations can be addressed with several surgical stabilization techniques. The aim of this in vitro study was to evaluate biomechanical features of the native joint compared with 3 different stabilization methods: locking hook plate (HP), TightRope (TR), and bone anchor system (AS).

Hypothesis: The HP provides higher stiffness than the anatomic reconstruction techniques.

Study Design: Controlled laboratory study.

Methods: A new biomechanical in vitro model of the AC joint was used to analyze joint stability after surgical repair (HP, TR, and AS). Eighteen cadaveric specimens were randomized for bone density and diameter in the midclavicle section. Joint stiffness was measured by applying an axial load and a defined physiological range of motion for internal and external rotations and upward and downward rotations. Data were recorded at 3 stages: for the native joint after dissecting the AC ligaments, directly after repair, and after axial cyclic loading (1000 cycles with 20 and $70 \mathrm{~N}$ at $1 \mathrm{~Hz}$ ). To evaluate which implant mimics physiological joint properties best, axial stiffness of vertical stability was assessed in combination with rotation. Finally, static loading in the superior direction was applied until failure of the joints occurred.

Results: Axial stiffness of the TR and AS groups was 2-fold higher than for the HP group and the native joint $(67.1,66.1$, and $22.5 \mathrm{~N} / \mathrm{mm}$, respectively; $P<.004)$. Decreased load-to-failure rates were recorded in the HP group compared with the TR and AS groups $(248.9 \pm 72.7,832.0 \pm 401.4$, and $538.0 \pm 166.1 \mathrm{~N}$, respectively). The stiffness of the rotations was not significantly different between the treatment methods but was lower in horizontal and downward rotations compared with the native state. Thus, native AC ligaments contributed a significant share to joint stiffness.

Conclusion: The TR and AS groups demonstrated higher vertical load capacity. Compared with the TR and AS, the HP demonstrated an axial stiffness closest to the native joint. For restoring physiological properties, reconstruction of the AC ligaments may be necessary.

Clinical Relevance: The results show different biomechanical properties of the HP and anatomic reconstructions.

Keywords: AC joint dislocation; hook plate; TightRope; anchor reconstruction; biomechanics of AC joint

*Address correspondence to Jakob V. Nüchtern, MD, University Medical Center Hamburg-Eppendorf, Department of Trauma, Hand and Reconstructive Surgery, Martinistrasse 52, 20246, Hamburg, Germany (e-mail: j.nuechtern@uke.de).

${ }^{\dagger}$ Department of Trauma, Hand and Reconstructive Surgery, University Medical Center Hamburg-Eppendorf, Hamburg, Germany.

${ }^{\ddagger}$ Biomechanics Section, Hamburg University of Technology, Hamburg, Germany.

SDepartment of Forensic Medicine, University Medical Center Hamburg-Eppendorf, Hamburg, Germany.

The authors declared that they have no conflicts of interest in the authorship and publication of this contribution.

The American Journal of Sports Medicine, Vol. 41, No. 6 DOI: $10.1177 / 0363546513484892$

(c) 2013 The Author(s)
Traumatic acromioclavicular (AC) joint dislocations are common injuries. The typical trauma mechanism is a direct fall on the ipsilateral arm. ${ }^{33}$ Lesions of the AC joint are classified according to Rockwood grades (I-VI) ${ }^{25,31}$ Grade IV to VI lesions are commonly treated surgically. The treatment of type III injuries remains controversial. ${ }^{21,23}$ $\mathrm{A}$ basic principle in the treatment of acute $\mathrm{AC}$ joint dislocations is the restoration of joint congruity and mechanical stability as accurately as possible to provide physiological conditions for the development of rigid scar tissue healing. ${ }^{16}$ The hook plate is a commonly used stabilization device for functional $\mathrm{AC}$ joint restoration and reduction maintenance. ${ }^{4,8,9,12,14,30}$ Recently, less invasive implant systems such as the Flipptack (Karl Storz, Tuttlingen, 

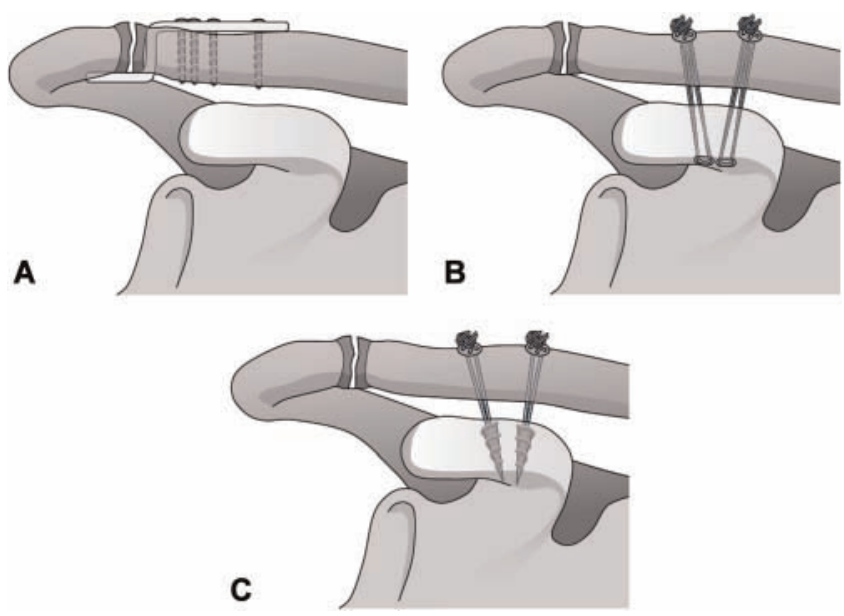

Figure 1. Line drawings of the 3 different methods: $(A)$ hook plate, (B) TightRope, and (C) anchor system.

Germany) and TightRope (Arthrex GmbH, Munich, Germany) have been introduced, aspiring toward a first-choice implant. $^{32,33}$ The use of 2 bone anchors also offers an attractive alternative in minimally invasive $\mathrm{AC}$ joint stabilization. ${ }^{1}$ An obvious advantage of these reconstruction techniques is assisted arthroscopic instrumentation and the absence of the need for implant removal, which is necessary in using the hook plate.

The aim of this in vitro biomechanical study was to compare AC joint stability after surgical repair using 3 common surgical techniques. We hypothesized that the hook plate would provide higher stiffness in the superior direction and lower stiffness in internal and external rotations compared with the native joint and the anatomic reconstruction techniques.

\section{MATERIALS AND METHODS}

A total of 18 shoulder specimens were randomized for bone mineral density (BMD) and clavicular diameter. The 3 different groups were compared with respect to bone density, dislocation, and stiffness of the native AC joints. We used a locking hook plate (LCP Hook Plate, Synthes GmbH, Solothurn, Switzerland) and 2 different anatomic reconstruction systems of the coracoclavicular ligament. In the first group, 2 second-generation TightRopes with No. 5 FiberWire (Arthrex $\mathrm{GmbH}$ ) were used. In the second group, 2 bone anchor systems with two 6.5-mm corkscrew anchors loaded with FiberTape (Arthrex $\mathrm{GmbH}$ ) were implanted. The FiberTape was fixed over 2 small plates above the clavicle according to the clavicular plates of the second-generation TightRope system. The different reconstructions (hook plate [HP], TightRope [TR], and bone anchor system [AS]) were used in 6 specimens each (Figure 1).

The joints were removed postmortem at the Department of Forensic Medicine, University Medical Center HamburgEppendorf, and stored at $-20^{\circ} \mathrm{C}$. Each specimen included the complete scapula and clavicle with an intact

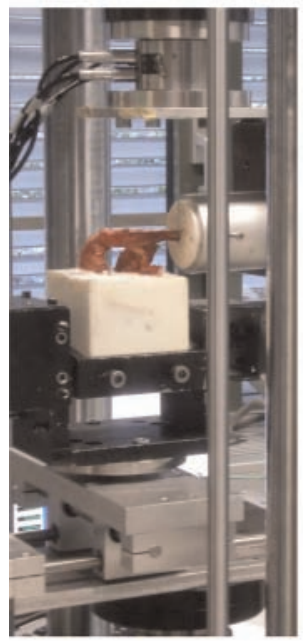

A

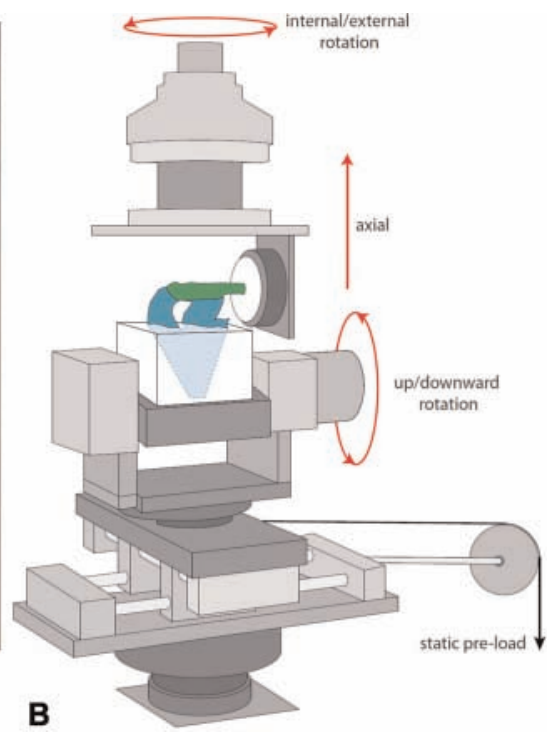

Figure 2. Biomechanical model. (A) Photograph of materials testing machine setting with specimen. (B) Schematic drawing of materials testing machine setting.

deltotrapezial fascia. The humerus was exarticulated. All specimens underwent fluoroscopic and clinical examinations. Specimens demonstrating prior fractures, ossifications, or former injuries of the $\mathrm{AC}$ and coracoclavicular ligaments ${ }^{3}$ were excluded. Bone density of the lateral clavicle was determined for each specimen using peripheral quantitative computed tomography (pQCT) (XCT 2000, Stratec, Pforzheim, Germany).

The fresh-frozen specimens were thawed overnight at room temperature. The soft tissue was removed from the inferior scapula up to the processus spinatus and $80 \mathrm{~mm}$ along the medial clavicle. The inferior scapula was embedded in a polyurethane block (ureol FC53, Gößl \& Pfaff, Karlskron, Germany) in a functional neutral position at $5^{\circ}$ of upward rotation in the anterior-posterior direction and $20^{\circ}$ of tilt to the axial plane. Before testing, the AC joints were fixed in a neutral position using K-wire arthrodesis to avoid lesions of the ligaments. The coracoid process was localized $1 \mathrm{~cm}$ above the polyurethane block, and the medial clavicle was embedded up to $80 \mathrm{~mm}$ to the lateral end in a 0.2-L cup. The setup of the materials testing machine (MTS Bionics Mini II, MTS Systems Corp, Eden Prairie, Minnesota) was based on the figures in the work of Fukuda et al,${ }^{10}$ completed with an X-Y table, two 6 degrees of freedom load cells, and a hydraulic rotary axis (Figure 2).

Joint stiffness was measured for each specimen within the normal range of motion under cyclic superior loading for 3 cycles. First, the stiffness was measured in the axial superior direction (20 and $70 \mathrm{~N}$ ), followed by internal and external rotations $\left(15^{\circ}, 0^{\circ}, 15^{\circ}\right)$ and upward and downward rotations of the scapula $\left(12^{\circ}, 0^{\circ}, 12^{\circ}\right)$. Upward rotation simulated abduction of the arm, and downward rotation simulated adduction of the arm. Internal and external rotations reproduce anteversion and retroversion of the arm in $90^{\circ}$ of elevation, respectively. The range of rotations was defined 
according to Ludewig et al. ${ }^{18}$ An axial load of $70 \mathrm{~N}$ has been described by several authors. ${ }^{19,20,33,35}$ The 3 -fold repetition was performed to obtain exploitable and comparable mean values.

Specimens underwent identical testing sequences in their native state, after dissecting the AC ligaments, after cutting the coracoclavicular ligaments and implantation of a reconstruction device, and after cyclic loading (Figure 2). Cyclic loading with 20 and $70 \mathrm{~N}$ was applied sinusoidally for 1000 cycles at $1 \mathrm{~Hz}$ in a superior direction, which represents $10 \%$ of a mild postoperative physical therapy stress protocol. ${ }^{33}$ At the end, final load-to-failure testing was performed using a static increasing axial load at a rate of $25 \mathrm{~mm} / \mathrm{min} .^{7,13,17}$ Failure was defined as a $20-\mathrm{mm}$ superior dislocation or any fracture, insufficiency, or material failure occurrence. Photographic and radiographic documentation was obtained in every case.

Implantation of the HP was performed according to the manufacturer's guidelines. Four-hole locking plates were used. The offset of the hook $(12,15$, or $18 \mathrm{~mm})$ was determined according to the anatomy.

Two TRs with No. 5 FiberWire were implanted to reconstruct the anatomic V-shaped alignment of the coracoclavicular ligaments from the superior clavicle to the base of the coracoid process. ${ }^{27}$ The footprints of the coracoclavicular ligaments were identified on each specimen. The drill guide followed the $\mathrm{V}$-shaped running center of the trapezoid and conoid ligaments at their clavicular origins to the base of the coracoid process. The trapezoid insertion is localized approximately $2.5 \mathrm{~cm}$ and the conoid approximately $4.5 \mathrm{~cm}$ medial to the lateral end of the clavicle. ${ }^{32}$ Special importance was paid to the distance between both footprints as to not underrun the critical $10-\mathrm{mm}$ limit. ${ }^{27}$

The second anatomic ligament reconstruction technique with the AS was performed using FiberTape threads fixed to the coracoid process using two 6.5-mm screw anchors (Corkscrew III, Arthrex GmbH). The tape was fixed over the clavicle using 2 small plates. The implantation, especially the drillings, was performed as described above.

All surgical procedures were performed by 1 experienced orthopaedic surgeon (L.G.G.). Approval of the ethics committee for this study was granted.

\section{Statistical Analysis}

Joint stiffness was determined for all range of motion directions from a linear regression slope to the loaddisplacement curves. These were compared before and after surgery both within and between each treatment.

Data were proven to be normally distributed regarding a specific parameter using the Shapiro-Wilk test. The homogeneity of variance between groups was verified by the Levene test. Regarding the results of these statistical tests, parametric (1-way/2-way analysis of variance [ANOVA] or Welch test) or nonparametric (Kruskal-Wallis test) analysis was performed.

The influence of the time at which the data were recorded (native vs after surgery vs after cyclic loading) on the stiffness of the specimens was assessed using a repeated-measures design. In case of an additional independent variable, mixed ANOVA was performed. The Mauchly test was used to indicate whether the assumption of sphericity had to be violated. In case of a significant Mauchly test result $(P<$ .05), a Greenhouse-Geisser correction was applied. For all statistical tests, the type I error probability was set to $\alpha=$ .05. All statistical tests were calculated by means of PASW Statistics v18 (SPSS Inc, Chicago, Illinois).

\section{RESULTS}

Within the 3 groups, no significant differences were found regarding the clavicular diameter $(P=.136$, 1-way ANOVA), bone density ( $P=.224,1$-way ANOVA), native superior translation $(20$ and $70 \mathrm{~N})(.312 \leq P \leq .460$, 1-way ANOVA), native rotation (upward and downward, internal and external) $(.103 \leq P \leq .774$, Kruskal-Wallis test), and native axial stiffness $(P=.135$, Kruskal-Wallis test) (Table 1).

Mean BMD values of the lateral clavicle were $242.4 \pm$ $37.6 \mathrm{mg} / \mathrm{cm}^{3}\left(220.4 \pm 45.9 \mathrm{mg} / \mathrm{cm}^{3}\right.$ in the HP group, $253.5 \pm 31.6 \mathrm{mg} / \mathrm{cm}^{3}$ in the TR group, and $253.2 \pm$ $28.7 \mathrm{mg} / \mathrm{cm}^{3}$ in the AS group) ( $P=.224,1$-way ANOVA). Mean superior translation of all native joints was $2.9 \pm$ $1.5 \mathrm{~mm}$ with the $20-\mathrm{N}$ axial load and $5.0 \pm 1.7 \mathrm{~mm}$ with the 70-N load (Table 1). Mean natural joint stiffness for each rotation was $25.34 \pm 7.05 \mathrm{~N} / \mathrm{mm}$ (axial), $0.056 \pm$ $0.026 \mathrm{~N} \cdot \mathrm{m} / \mathrm{deg}$ (internal rotation) and $0.414 \pm 0.339 \mathrm{~N} \cdot \mathrm{m} /$ $\mathrm{deg}$ (external rotation), and $0.245 \pm 0.11 \mathrm{~N} \cdot \mathrm{m} / \mathrm{deg}$ (upward rotation) and $0.443 \pm 0.592 \mathrm{~N} \cdot \mathrm{m} / \mathrm{deg}$ (downward rotation) (Table 2).

After dissection, axial stiffness of the AC ligaments was $15 \%$ lower $(25.34 \pm 7.05 \mathrm{~N} / \mathrm{mm}$ [native] vs $21.54 \pm$ $7.29 \mathrm{~N} / \mathrm{mm})(P<.001$, mixed ANOVA), and a significant loss of stiffness was observed for each rotation. Stiffness in upward rotation was reduced by $18 \%(0.245 \pm 0.11 \mathrm{~N} \cdot \mathrm{m} / \mathrm{deg}$ [native] vs $0.201 \pm 0.104 \mathrm{~N} \cdot \mathrm{m} / \mathrm{deg})(P=.004, \operatorname{mixed}$ ANOVA), stiffness in downward rotation by $59 \%(0.443 \pm 0.592 \mathrm{~N} \cdot \mathrm{m} /$ $\operatorname{deg}$ [native] vs $0.18 \pm 0.148 \mathrm{~N} \cdot \mathrm{m} / \mathrm{deg})(P=.029$, mixed ANOVA), stiffness in internal rotation by $41 \%(0.056 \pm$ $0.026 \mathrm{~N} \cdot \mathrm{m} / \mathrm{deg}$ [native] vs $0.033 \pm 0.009 \mathrm{~N} \cdot \mathrm{m} / \mathrm{deg})(P=.002$, mixed ANOVA), and stiffness in external rotation by $85 \%$ $(0.414 \pm 0.339 \mathrm{~N} \cdot \mathrm{m} / \mathrm{deg}$ [native] vs $0.063 \pm 0.048 \mathrm{~N} \cdot \mathrm{m} / \mathrm{deg})$ $(P<.001$, mixed ANOVA) (Table 2$)$.

Postoperative failure during range of motion testing occurred only in 2 of 6 specimens within the HP group. Failure occurred within the first cycles of axial superior loading directly after implantation. The failures were clavicle fractures localized at the medial screw.

Mean superior translation in the HP group was $7.32 \pm$ $3.57 \mathrm{~mm}$ under the $20-\mathrm{N}$ axial load and $9.34 \pm 3.78 \mathrm{~mm}$ under the $70-\mathrm{N}$ load (Table 1). Stiffness patterns of the HP group are presented in Table 2. The mean maximum load-to-failure values attained in the HP specimens were $248.9 \pm 72.7 \mathrm{~N}$ (Table 1).

The TR-implanted joints showed a mean superior translation of $2.04 \pm 1.17 \mathrm{~mm}$ under the $20-\mathrm{N}$ axial load and $2.83 \pm 1.00 \mathrm{~mm}$ under the $70-\mathrm{N}$ axial load after cyclic testing (Table 1). Stiffness patterns of the TR group are presented in Table 2. 
TABLE 1

Mean Loads to Failure, Clavicular Diameters, and Native and Postoperative Superior Translations ${ }^{a}$

\begin{tabular}{|c|c|c|c|c|c|c|c|c|}
\hline Group & $\begin{array}{l}\text { Load to } \\
\text { Failure, N }\end{array}$ & $\begin{array}{l}\text { Clavicular } \\
\text { Diameter, } \\
\text { mm }\end{array}$ & $\begin{array}{c}\text { Native } \\
\text { Superior } \\
\text { Translation } \\
\text { at } 20 \mathrm{~N}, \mathrm{~mm}\end{array}$ & $\begin{array}{c}\text { Native } \\
\text { Superior } \\
\text { Translation } \\
\text { at } 70 \mathrm{~N}, \mathrm{~mm}\end{array}$ & $\begin{array}{l}\text { Postoperative } \\
\text { Superior } \\
\text { Translation } \\
\text { at } 20 \mathrm{~N}, \mathrm{~mm}\end{array}$ & $\begin{array}{l}\text { Postdynamic } \\
\text { Superior } \\
\text { Translation } \\
\text { at } 20 \mathrm{~N}, \mathrm{~mm}\end{array}$ & $\begin{array}{c}\text { Postoperative } \\
\text { Superior } \\
\text { Translation } \\
\text { at } 70 \mathrm{~N}, \mathrm{~mm}\end{array}$ & $\begin{array}{l}\text { Postdynamic } \\
\text { Superior } \\
\text { Translation } \\
\text { at } 70 \mathrm{~N}, \mathrm{~mm}\end{array}$ \\
\hline Hook plate & $248.9 \pm 72.7$ & $10.1 \pm 0.7$ & $2.40 \pm 0.31$ & $4.86 \pm 0.73$ & $4.06 \pm 1.47$ & $7.32 \pm 3.57$ & $6.63 \pm 2.03$ & $9.34 \pm 3.78$ \\
\hline TightRope & $832.0 \pm 401.4$ & $10.8 \pm 0.7$ & $2.48 \pm 1.17$ & $4.26 \pm 1.36$ & $1.30 \pm 0.91$ & $2.04 \pm 1.17$ & $2.13 \pm 0.78$ & $2.83 \pm 1.00$ \\
\hline Anchor system & $538.0 \pm 166.1$ & $11.1 \pm 1.1$ & $3.71 \pm 1.36$ & $5.40 \pm 1.60$ & $4.90 \pm 1.75$ & $5.99 \pm 1.89^{b}$ & $5.72 \pm 1.81$ & $6.74 \pm 1.98^{b}$ \\
\hline
\end{tabular}

${ }^{a}$ Data are expressed as mean \pm standard deviation.

${ }^{b}$ Statistically significant difference compared with the native joint.

TABLE 2

Stiffness of the Different Systems Compared With the Native Joint ${ }^{a}$

\begin{tabular}{|c|c|c|c|c|c|}
\hline & \multicolumn{4}{|c|}{ Rotation Stiffness, N.m/deg } & \multirow[b]{2}{*}{ Axial Stiffness, N/mm } \\
\hline & Internal Rotation & External Rotation & Upward Rotation & Downward Rotation & \\
\hline Native joint & $0.056 \pm 0.026$ & $0.414 \pm 0.339$ & $0.245 \pm 0.113$ & $0.443 \pm 0.592$ & $25.34 \pm 7.05$ \\
\hline Native joint without AC ligament & $0.033 \pm 0.009^{b}$ & $0.063 \pm 0.048^{b}$ & $0.201 \pm 0.104^{b}$ & $0.18 \pm 0.148^{b}$ & $21.54 \pm 7.29^{b}$ \\
\hline \multicolumn{6}{|l|}{ Hook plate } \\
\hline Postoperative & $0.016 \pm 0.007^{b}$ & $0.133 \pm 0.182^{b}$ & $0.173 \pm 0.017$ & $0.173 \pm 0.086^{b}$ & $19.15 \pm 4.86$ \\
\hline Postdynamic & $0.019 \pm 0.001^{b}$ & $0.146 \pm 0.122^{b}$ & $0.231 \pm 0.032$ & $0.175 \pm 0.041^{b}$ & $22.54 \pm 3.04$ \\
\hline \multicolumn{6}{|l|}{ TightRope } \\
\hline Postoperative & $0.033 \pm 0.011^{b}$ & $0.054 \pm 0.017^{b}$ & $0.228 \pm 0.088$ & $0.149 \pm 0.049^{b}$ & $60.52 \pm 17.50^{b}$ \\
\hline Postdynamic & $0.037 \pm 0.01^{b}$ & $0.055 \pm 0.018^{b}$ & $0.242 \pm 0.083$ & $0.16 \pm 0.043^{b}$ & $67.12 \pm 20.00^{b}$ \\
\hline \multicolumn{6}{|l|}{ Anchor system } \\
\hline Postoperative & $0.054 \pm 0.03^{b}$ & $0.047 \pm 0.022^{b}$ & $0.233 \pm 0.127$ & $0.162 \pm 0.038^{b}$ & $67.12 \pm 20.00^{b}$ \\
\hline Postdynamic & $0.053 \pm 0.026^{b}$ & $0.049 \pm 0.021^{b}$ & $0.259 \pm 0.111$ & $0.179 \pm 0.042^{b}$ & $66.15 \pm 17.20^{b}$ \\
\hline
\end{tabular}

${ }^{a}$ Data are expressed as mean \pm standard deviation.

${ }^{b}$ Statistically significant difference compared with the native joint.

The specimens that underwent an AS implantation demonstrated a mean superior translation of $5.99 \pm$ $1.89 \mathrm{~mm}$ with the $20-\mathrm{N}$ axial load and $6.74 \pm 1.98 \mathrm{~mm}$ with the 70-N axial load (Table 1). Stiffness patterns of the AS group are presented in Table 2.

The superior translation of the HP-implanted joints with $20-\mathrm{N}$ and $70-\mathrm{N}$ axial loads tended to be influenced by the time of data acquisition (HP with $20 \mathrm{~N}$ : $2.40 \pm$ $0.31 \mathrm{~mm}$ [native] vs $7.32 \pm 3.57 \mathrm{~mm}$ [postdynamic], $P=$ .059 ; HP with $70 \mathrm{~N}: 4.86 \pm 0.73 \mathrm{~mm}$ [native] vs $6.63 \pm$ $2.03 \mathrm{~mm}$ [postoperative] vs $9.34 \pm 3.78 \mathrm{~mm}$ [postdynamic], $P=.082$ ). No significant increase of dislocations after surgery or cyclic loading compared with the native situation was found within the HP group (Table 1).

With a superior translation at $70 \mathrm{~N}$, the TR-implanted joints showed a trend to be smaller after surgery (4.26 \pm $1.36 \mathrm{~mm}$ [native] vs $2.13 \pm 0.78 \mathrm{~mm}$ [postoperative] vs $2.83 \pm 1.00 \mathrm{~mm}$ [postdynamic]; $P=.086$ ). At $20 \mathrm{~N}$, no significant reduction of superior translation was observed in the TR group after surgery and cyclic loading (2.48 \pm $1.17 \mathrm{~mm}$ [native] vs $1.30 \pm 0.91 \mathrm{~mm}$ [postoperative] vs $2.04 \pm 1.17 \mathrm{~mm}$ [postdynamic]; $P=.220$ ).

After cyclic loading, the AS-repaired joints showed a significantly increased superior dislocation at $20 \mathrm{~N}$ as well as at $70 \mathrm{~N}$ compared with the native joints (AS with $20 \mathrm{~N}$ :
$3.71 \pm 1.36 \mathrm{~mm}$ [native] vs $5.99 \pm 1.89 \mathrm{~mm}$ [postdynamic], $P=.003 ; \mathrm{AS}$ with $70 \mathrm{~N}: 5.40 \pm 1.60 \mathrm{~mm}$ [native] vs $6.74 \pm$ $1.98 \mathrm{~mm}$ [postdynamic], $P=.027$ ). The dislocation increased about $1 \mathrm{~mm}$ after cyclic loading compared with the postoperative situation (Table 1).

A significant increase in axial stiffness in the TR and AS groups was found postoperatively $(P<.001$, ANOVA) in contrast to the HP group. The HP-treated specimens exhibited the same axial stiffness after surgical intervention as in the native state. Axial stiffness of the HP group was significantly smaller compared with the TR and AS groups $(P<.004$, Dunnett T3) (Figure 3A and Table 2).

The stiffness of the different rotations (upward, downward, internal, and external), independent of the acquired time, was not significantly different between the HP, TR, and AS groups (upward rotation: $P=.496$; downward rotation: $P=.555$; internal rotation: $P=.134$; external rotation: $P=.429$; all mixed ANOVA) (Table 2). Postoperatively, mean external rotation of all treatment groups decreased significantly from $0.414 \pm 0.339 \mathrm{~N} \cdot \mathrm{m} /$ deg to $0.078 \pm 0.023 \mathrm{~N} \cdot \mathrm{m} / \mathrm{deg}(P=.003$, within-patient contrasts, mixed ANOVA). No differences in stiffness in external rotation occurred between the postoperative and postdynamic time points $(P>.999$, within-patient contrasts) (Table 2). 
A
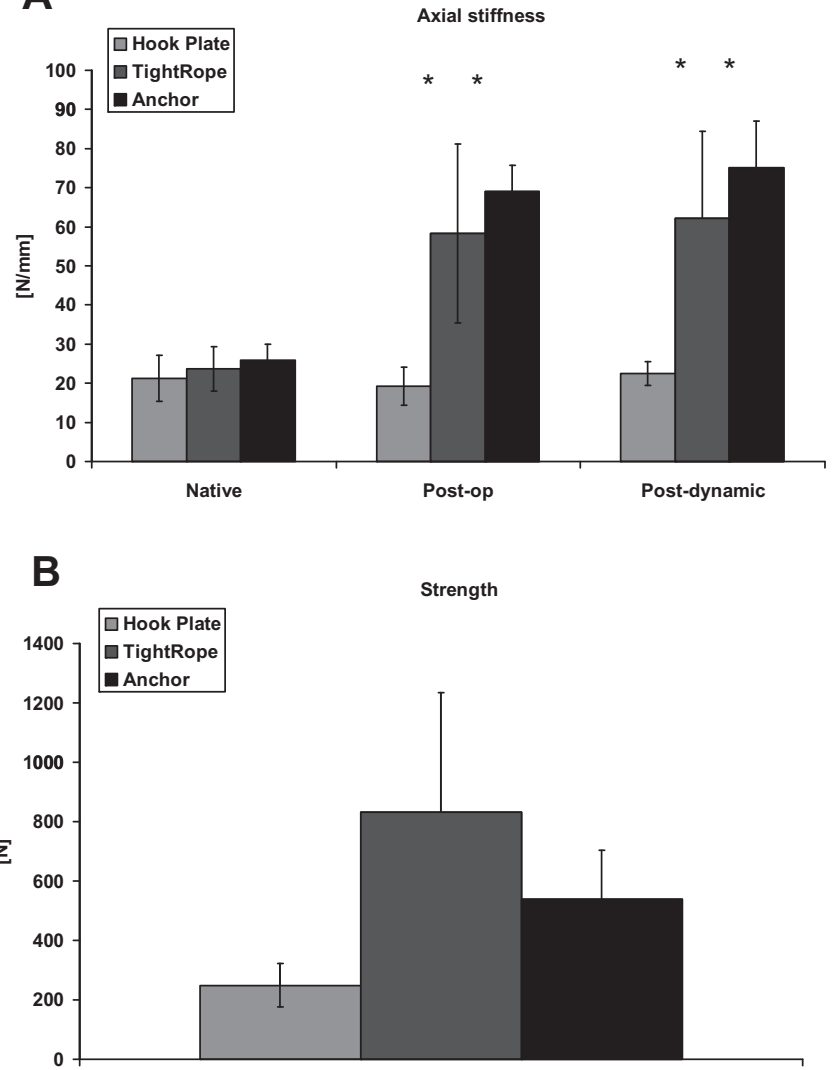

Figure 3. (A) Axial stiffness was higher in TightRope and anchor reconstructions compared with the native joint (postoperative and postdynamic). (B) Mean load-to-failure values by the static superior load.

Surgical intervention resulted independently of the treatment method in decreased stiffness in internal rotation $(0.056 \pm 0.026 \mathrm{~N} \cdot \mathrm{m} / \mathrm{deg}$ [native] vs $0.037 \pm$ $0.024 \mathrm{~N} \cdot \mathrm{m} / \mathrm{deg})(P=.038$, within-patient contrasts, mixed ANOVA) as well as in downward rotation $(0.443 \pm$ $0.592 \mathrm{~N} \cdot \mathrm{m} / \mathrm{deg}$ [native] vs $0.161 \pm 0.054 \mathrm{~N} \cdot \mathrm{m} / \mathrm{deg}$ ) ( $P=.016$, within-patient contrasts, mixed ANOVA) (Table 2 ). Stiffness in upward rotation was neither influenced by the implantation of a TR, AS, or HP nor by dynamic loading $(0.246 \pm 0.113 \mathrm{~N} \cdot \mathrm{m} / \mathrm{deg}$ [native] vs $0.216 \pm 0.093 \mathrm{~N} \cdot \mathrm{m} /$ deg [postoperative] vs $0.245 \pm 0.082 \mathrm{~N} \cdot \mathrm{m} / \mathrm{deg}$ [postdynamic]) ( $P=.172$, mixed ANOVA). The mean load-tofailure value by the static superior load tended to be $30 \%$ greater in the TR group $(832.0 \pm 401.4 \mathrm{~N})$ compared with the AS group $(538.0 \pm 166.1 \mathrm{~N})$ and was $65 \%$ greater compared with the HP group $(248.9 \pm 72.7 \mathrm{~N}$ ) (Figure $3 \mathrm{~B}$ and Table 1).

The failure patterns for the HP during load-to-failure testing were fractures of the clavicle initiated at the medial screw hole and migration of the hook into the acromion (Figure 4), whereas the TR showed in all cases a cutout of the coracoid buttons (Figure 5): twice in the simulated conoid ligament position, once in the simulated trapezoid ligament position, and twice at both positions. The AS implants always failed because of bending of the bar on which the FiberTape was drawn around in the anchor; thus, the bar and the tape dislocated the anchor (Figure $6)$. The anchor remained in the coracoid.

\section{DISCUSSION}

The treatment principle of acute AC joint dislocations is the restoration of physiological joint biomechanics and the maintenance of range of motion and mechanical stability. ${ }^{16}$ Therefore, the range of motion of the native state of an intact joint should be tested and compared with the instrumented joint. Reviewing the literature, common biomechanical apparatuses test the clavicular movement only in superior and anteroposterior directions. ${ }^{5,13,19,20,32,34,35}$ Findings by Sahara et $\mathrm{al}^{26}$ showed an anteroposterior translation of only $1.9 \mathrm{~mm}$ posterior and $1.6 \mathrm{~mm}$ anterior and a superoinferior translation of $0.9 \mathrm{~mm}$ during arm abduction in the native state in healthy male participants. The AC joint allows the rotation of the scapula relative to the clavicle in different planes. Inman et $\mathrm{al}^{15}$ and Graichen et $\mathrm{al}^{11}$ reported an in vivo motion of the AC joint of approximately $20^{\circ}$. The data of Ludewig et al ${ }^{18}$ demonstrated a maximum mean movement of $17^{\circ}$ of internal rotation and $11^{\circ}$ of upward rotation. Former studies suggested evaluation in a multiplanar setting that reflects the in vivo situation more accurately in terms of rotations than the measurements of anteroposterior and superior displacements. ${ }^{16}$ An aim of this cadaveric study was to establish a biomechanical setup that imitates the range of motion of the native AC joint. Therefore, we tested the native intact joint in internal, external, upward, and downward rotations in combination with an axial load that mimics a weight stress of the ipsilateral arm.

The loss of stiffness after dissection of the AC ligaments is comparable with that found by Fukuda et al. ${ }^{10}$ According to their opinion, the AC ligament is the major contributor especially for small anterior/posterior displacements.

Another aim was to examine the quality of native joint property restoration by comparing 3 different commonly used devices. The HP is still one of the most commonly used implants for acute AC dislocations with good clinical and biomechanical results. ${ }^{4,9,12,14,30}$ McConnell et al, ${ }^{20}$ for example, reported physiological stiffness. The axial stiffness values of the intact joint and the HP reported in this study are comparable with those reported by McConnell et al ${ }^{20}$ (intact: $24.1 \mathrm{~N} / \mathrm{mm}$ [current study] vs $24.6 \mathrm{~N} / \mathrm{mm}$ [McConnell et $\mathrm{al}^{20}$ ]; HP: $22.5 \mathrm{~N} / \mathrm{mm}$ [current study] vs $25.5 \mathrm{~N} / \mathrm{mm}$ [McConnell et $\left.\mathrm{al}^{20}\right]$ ).

The 2 postoperative failures in the HP group might have been related to inferior bone density and the small diameter of the clavicles. The BMD values of the lateral clavicles of these 2 joints were among the lowest of all specimens (197.0 and $212.6 \mathrm{mg} / \mathrm{cm}^{3}$; the mean value of all specimens was $242.4 \pm 37.6 \mathrm{mg} / \mathrm{cm}^{3}$ ). Wellmann et $\mathrm{al}^{33}$ reported increased mean BMD values. However, the exact parameter of data acquisition of the BMD was not described, and the measured area of the clavicle and the procedure used (dual-energy x-ray absorptiometry [DEXA] or pQCT) 

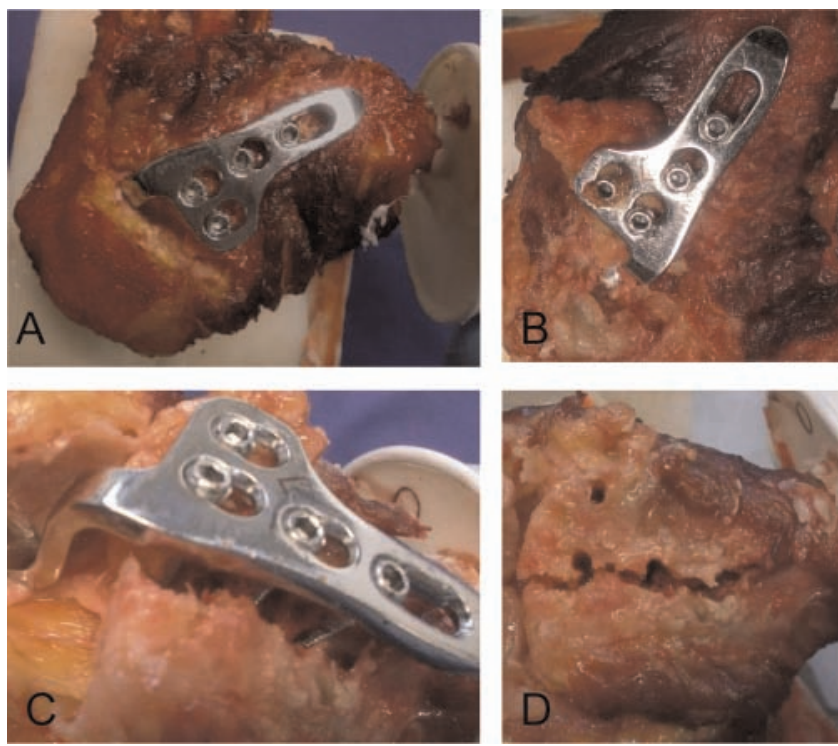

Figure 4. Failure patterns for the hook plate (photographs from superior view). (A) Specimen with a hook plate in situ. (B) Specimen with the hook broken into the acromion. (C) Specimen with a fracture of the clavicle through the screw bearings. (D) Specimen with a fracture of the clavicle through the screw bearings without the plate.
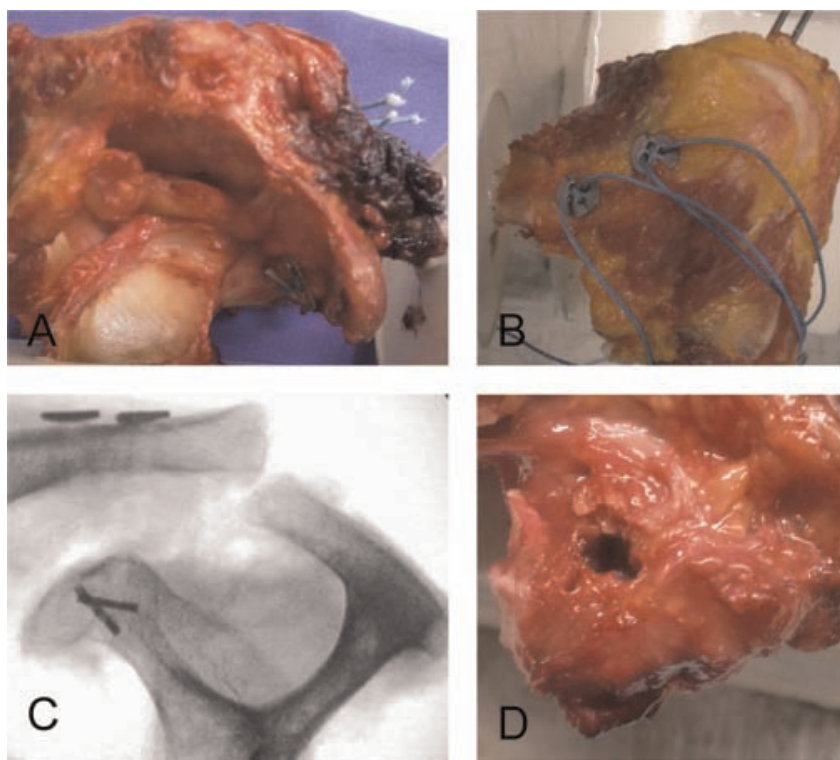

Figure 5. Failure patterns for the TightRope. (A) Photograph from lateral view: specimen with the inferior plates of the TightRope underneath the base of the coracoid. (B) Photograph from superior view: specimen with the superior plates of the TightRope. (C) C-arm shot, Y-view: a fracture of the coracoid and the inferior plates cut out through the coracoid process. (D) Photograph from inferior view to the base of the coracoid: a fracture of the coracoid and the inferior plates breaking through the process.
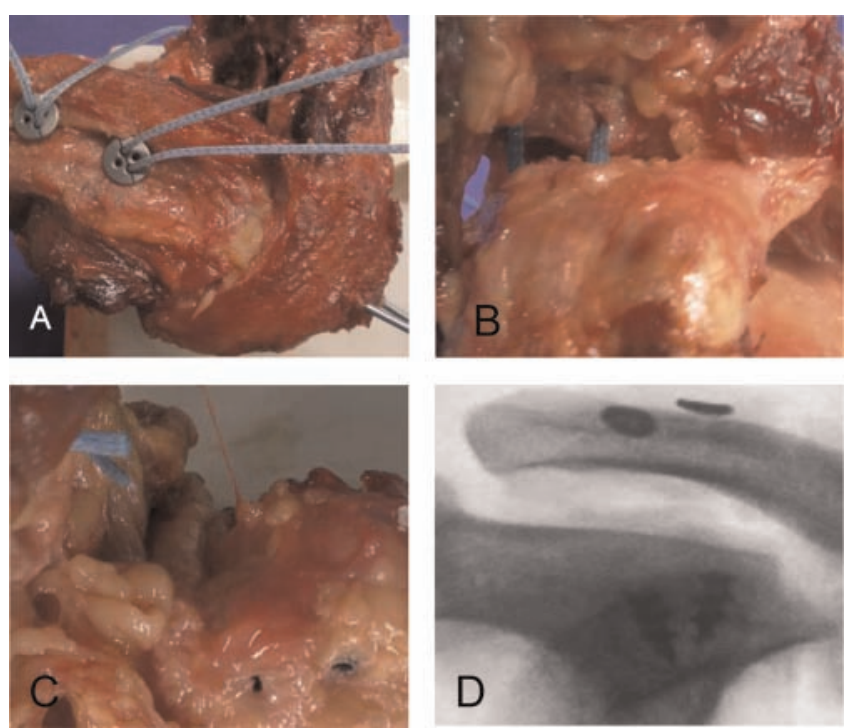

Figure 6. Failure patterns for the anchor system. (A) Photograph from superior view: specimen with the superior plates of the TightRope with FiberTape. (B) Photograph from ventral view: specimen with the FiberTape from the coracoid process into the clavicle. (C) Photograph from superior view to the base of the coracoid: in situ anchors in the base of the coracoid and intact FiberTape underneath the clavicle. (D) C-arm shot, Y-view: lying anchors in the coracoid and the plates above the clavicle.

were not mentioned. The data are therefore not fully comparable. The superior-inferior diameters of the premature failed clavicles were again the lowest of all tested specimens: 9.0 and $9.9 \mathrm{~mm}$. The mean diameter of all clavicles was $10.7 \pm 0.9 \mathrm{~mm}$. Rios et $\mathrm{al}^{24}$ reported a mean superior-inferior diameter of $11.4 \pm 1.6 \mathrm{~mm}$. Both specimens failed under an axial load. The load-to-failure values during the sinusoidal loads were only 49.5 and $83.6 \mathrm{~N}$. Both clavicles fractured around the medial screw of the HP. In our opinion, the fractures were caused by potentially associated osteoporosis. Therefore, patients with osteoporosis are usually treated nonoperatively.

An advantage of the HP is the relatively easy implantation procedure and early postoperative mobilization. However, known disadvantages of the HP are recurrent dislocations $^{12}$ and skin/wound complications, ${ }^{30}$ and Folwaczny et $\mathrm{al}^{9}$ noted only a $63.2 \%$ patient satisfaction rate postoperatively. The main disadvantage is the necessity of implant removal. Common complications, as also seen in this study, are the migration of the hook into the subacromial bone and fractures of the clavicle around the medial screw of the plate. ${ }^{16,20}$

The double button system such as the TR is a more recently developed implant, which is increasingly used with good results. Walz et $\mathrm{al}^{32}$ reported a double TR fixation with equal or even higher maximum forces compared with native ligaments. They described an ultimate tensile strength up to $982 \mathrm{~N}$ and stiffness up to $80 \mathrm{~N} / \mathrm{mm}$ in a static vertical testing procedure. ${ }^{32}$ 
As described previously, the cutout of the coracoid plates has been demonstrated in the present study as well. ${ }^{16,35}$ Wellmann et $\mathrm{al}^{35}$ tested subcoracoid flip button fixation (Flipptack), a PDS sling, and 2 different suture anchors (3.5- and 5.0-mm suture anchors, Smith \& Nephew, Memphis, Tennessee) using a porcine metatarsal model. The flip button and the sling revealed higher loads than the anchor repairs. A disadvantage of the double button systems may be the increased axial stiffness as seen in our results and in the literature. ${ }^{16}$

The anchor repair is performed in various ways. There are some publications reporting good results. Shin et $\mathrm{al}^{29}$ demonstrated a reliable technique for restoring stability by using 2 suture anchors. Choi et $\mathrm{al}^{2}{ }^{2}$ for example, did not observe a fixation failure. The specific reasons for failure of an anchor repair are suture insufficiency or anchor pullout. ${ }^{13}$ In this study, the anchors remained in place, and the FiberTape did not rupture. In our series, mainly the threads were pulled out of the anchor. Desmukh et $\mathrm{al}^{5}$ also tested different anchor repair systems (only 1 anchor each) and described the laxity in anteroposterior and superior directions under a 100-N load as well as failure load. The superior laxity that was similar to the superior translation was in the native state with $3.1 \pm 1.5 \mathrm{~mm}$ and the anchors from 6.0 to $9.0 \mathrm{~mm}$. Load-to-failure testing of the anchors by static superior loading provided a mean value from $278 \mathrm{~N}$ to $369 \mathrm{~N} .{ }^{5}$ Harris et al ${ }^{13}$ reported unidirectional static testing of 2 Mitek G4 Super Anchors (Mitek, Norwood, Massachusetts) with a rate of $25 \mathrm{~mm} / \mathrm{min}$ and a mean of $366 \pm 96 \mathrm{~N}$. Compared with our results, the mean values are lower.

The cutout of the TR or failure of the anchor could be caused by the 2 -fold higher stiffness compared with the native joint. Walz et al ${ }^{32}$ suggested the quadrupled FiberWire as an explanation for the extended stiffness. A removal of these systems may permit a prevention of this failure mechanism. Whether the high axial stiffness might lead to a cutout of the inferior buttons of the TR has to be addressed by clinical follow-up studies. ${ }^{22}$

In this study, a significant reduction of stiffness in internal and external rotations and downward rotation in every group was seen. This means that none of the reconstructions addresses the horizontal movement of the AC joint properly. Horizontal instability produces significantly inferior results in AC-specific scoring systems. ${ }^{28}$

We saw a significant loss of stiffness in every rotation by testing the joint after dissecting only the AC ligaments. Specifically, the stiffness of the external rotation was reduced by $85 \%$. Reconstruction of the AC ligaments is needed to restore physiological joint properties in horizontal and downward rotations.

In vivo, a superior translation of less than $2 \mathrm{~mm}$ is described as an anatomic dislocation, of 2 to $4 \mathrm{~mm}$ as light, and of 4 to $8 \mathrm{~mm}$ as moderate. Greater than $8 \mathrm{~mm}$ is regarded as a failure of the reconstruction. ${ }^{6}$ On the basis of this scale, the TR resulted in an anatomic postoperative superior displacement, while the AS and HP resulted in moderate translations. Based on this scale, the HP showed a failure of reduction under a load of $70 \mathrm{~N}$. Compared with the native joint, the TR group tended to have a lesser translation at a load of $70 \mathrm{~N}$. The AS group showed a significantly higher translation compared with the native joint at 20 and $70 \mathrm{~N}$.

Higher maximum forces were attained in the TR and AS groups, which were similar to or exceeded the strength of the native ligaments $(500 \pm 134 \mathrm{~N}){ }^{13}$ The observed failure patterns of the different reconstructions are in line with those mentioned in the literature. ${ }^{16}$

The hypothesis that the HP is stiffer in the axial direction than the 2 anatomic reconstructions is not supported by the data of this study. Our results showed significantly higher axial stiffness in the TR and AS groups, while the HP group was quite similar to the intact joint. A clavicle with an implanted HP allows a situation in which the HP bends over the whole length of the clavicle. The reconstructions are armed with FiberWire/FiberTape and therefore may be the cause of the extended stiffness compared with the native state. Perhaps that is the reason why the anatomic reconstruction techniques showed higher rigidity especially in the superior direction.

If the aim of surgical reconstruction in acute $\mathrm{AC}$ joint dislocation is to reach increased maximum forces, anatomic reconstruction (TR and AS) may have an advantage in the restoration of stability. If aiming at the reconstruction of physiological axial stiffness, the HP should be the implant of choice. The additive reconstruction of the AC ligaments might represent the key procedure for restoring physiological conditions.

\section{Limitations}

A biomechanical model never reaches $100 \%$ of in vivo conditions. The specimens, of course, did not include the whole soft tissue of the shoulder. The rotator cuff and the conjoined tendons were dissected. These muscles have an influence on the $\mathrm{AC}$ joint, which we were not able to simulate in this study. Another limitation of this study is the age of the specimens and the potentially associated osteoporosis. The 2 postoperative failed specimens had the lowest bone densities of all tested bones.

The TR and AS were not implanted arthroscopically, so our data show no advantages or disadvantages of the minimally invasive techniques. The 1000 cycles may be too few to document long-term results. Therefore, further studies including more cycles are required to detect limitations of the TR and AS implants.

\section{REFERENCES}

1. Chernchujit B, Tischer $\mathrm{T}$, Imhoff AB. Arthroscopic reconstruction of the acromioclavicular joint disruption: surgical technique and preliminary results. Arch Orthop Trauma Surg. 2006;126(9):575-581.

2. Choi SW, Lee TJ, Moon KH, Cho KJ, Lee SY. Minimally invasive coracoclavicular stabilization with suture anchors for acute acromioclavicular dislocation. Am J Sports Med. 2008;36(5):961-965.

3. Costic RS, Labriola JE, Rodosky MW, Debski RE. Biomechanical rationale for development of anatomical reconstructions of coracoclavicular ligaments after complete acromioclavicular joint dislocations. Am J Sports Med. 2004;32(8):1929-1936. 
4. De Baets T, Truijen J, Driesen R, Pittevils T. The treatment of acromioclavicular joint dislocation Tossy grade III with a clavicle hook plate. Acta Orthop Belg. 2004;70(6):515-519.

5. Deshmukh AV, Wilson DR, Zilberfarb JL, Perlmutter GS. Stability of acromioclavicular joint reconstruction: biomechanical testing of various surgical techniques in a cadaveric model. Am J Sports Med. 2004;32(6):1492-1498.

6. Elser F, Chernchujit B, Ansah P, Imhoff AB. [A new minimally invasive arthroscopic technique for reconstruction of the acromioclavicular joint]. Unfallchirurg. 2005;108(8):645-649.

7. Erak S, Pelletier MH, Woods KR, Smith PN, Walsh WR. Acromioclavicular reconstructions with hamstring tendon grafts: a comparative biomechanical study. J Shoulder Elbow Surg. 2008;17(5):772-778.

8. Faraj AA, Ketzer B. The use of a hook-plate in the management of acromioclavicular injuries: report of ten cases. Acta Orthop Belg. 2001;67(5):448-451.

9. Folwaczny EK, Yakisan D, Sturmer KM. [The Balser plate with ligament suture: a dependable method of stabilizing the acromioclavicular joint]. Unfallchirurg. 2000;103(9):731-740.

10. Fukuda K, Craig EV, An KN, Cofield RH, Chao EY. Biomechanical study of the ligamentous system of the acromioclavicular joint. J Bone Joint Surg Am. 1986;68(3):434-440.

11. Graichen H, Stammberger $\mathrm{T}$, Bonel $\mathrm{H}$, et al. Magnetic resonancebased motion analysis of the shoulder during elevation. Clin Orthop Relat Res. 2000;370:154-163.

12. Graupe F, Dauer U, Eyssel M. [Late results of surgical treatment of Tossy III acromioclavicular joint separation with the Balser plate]. Unfallchirurg. 1995;98(8):422-426.

13. Harris RI, Wallace AL, Harper GD, Goldberg JA, Sonnabend DH, Walsh WR. Structural properties of the intact and the reconstructed coracoclavicular ligament complex. Am J Sports Med. 2000;28(1): 103-108.

14. Henkel T, Oetiker R, Hackenbruch W. [Treatment of fresh Tossy III acromioclavicular joint dislocation by ligament suture and temporary fixation with the clavicular hooked plate]. Swiss Surg. 1997;3(4):160-166.

15. Inman VT, Saunders JB, Abbott LC. Observations of the function of the shoulder joint: 1944. Clin Orthop Relat Res. 1996;330:3-12.

16. Ladermann A, Gueorguiev B, Stimec B, Fasel J, Rothstock S, Hoffmeyer P. Acromioclavicular joint reconstruction: a comparative biomechanical study of three techniques. J Shoulder Elbow Surg. 2013;22(2):171-178.

17. Lee SJ, Nicholas SJ, Akizuki KH, McHugh MP, Kremenic IJ, Ben-Avi S. Reconstruction of the coracoclavicular ligaments with tendon grafts: a comparative biomechanical study. Am J Sports Med. 2003;31(5):648-655.

18. Ludewig PM, Phadke V, Braman JP, Hassett DR, Cieminski CJ, Laprade RF. Motion of the shoulder complex during multiplanar humeral elevation. J Bone Joint Surg Am. 2009;91(2):378-389.

19. Mazzocca AD, Santangelo SA, Johnson ST, Rios CG, Dumonski ML, Arciero RA. A biomechanical evaluation of an anatomical coracoclavicular ligament reconstruction. Am J Sports Med. 2006;34(2):236246.
20. McConnell AJ, Yoo DJ, Zdero R, Schemitsch EH, McKee MD. Methods of operative fixation of the acromio-clavicular joint: a biomechanical comparison. J Orthop Trauma. 2007;21(4):248-253.

21. Murena L, Canton G, Vulcano E, Cherubino P. Scapular dyskinesis and SICK scapula syndrome following surgical treatment of type III acute acromioclavicular dislocations [published online March 30, 2012]. Knee Surg Sports Traumatol Arthrosc. doi:10.1007/s00167-012-1959-9.

22. Murena L, Vulcano E, Ratti C, Cecconello L, Rolla PR, Surace MF. Arthroscopic treatment of acute acromioclavicular joint dislocation with double flip button. Knee Surg Sports Traumatol Arthrosc. 2009;17(12):1511-1515.

23. Nuber GW, Bowen MK. Acromioclavicular joint injuries and distal clavicle fractures. J Am Acad Orthop Surg. 1997;5(1):11-18.

24. Rios CG, Arciero RA, Mazzocca AD. Anatomy of the clavicle and coracoid process for reconstruction of the coracoclavicular ligaments. Am J Sports Med. 2007;35(5):811-817.

25. Rockwood C Jr. Injuries in the acromioclavicular joint: subluxations and dislocations about the shoulder. In: Rockwood C Jr, Green D, eds. Fracture in Adults. Philadelphia: JB Lippincott; 1984:860-910.

26. Sahara W, Sugamoto K, Murai M, Tanaka H, Yoshikawa H. 3D kinematic analysis of the acromioclavicular joint during arm abduction using vertically open MRI. J Orthop Res. 2006;24(9):1823-1831.

27. Salzmann GM, Paul J, Sandmann GH, Imhoff AB, Schottle PB. The coracoidal insertion of the coracoclavicular ligaments: an anatomic study. Am J Sports Med. 2008;36(12):2392-2397.

28. Scheibel M, Droschel S, Gerhardt C, Kraus N. Arthroscopically assisted stabilization of acute high-grade acromioclavicular joint separations. Am J Sports Med. 2011;39(7):1507-1516.

29. Shin SJ, Yun YH, Yoo JD. Coracoclavicular ligament reconstruction for acromioclavicular dislocation using 2 suture anchors and coracoacromial ligament transfer. Am J Sports Med. 2009;37(2):346-351.

30. Sim E, Schwarz N, Hocker K, Berzlanovich A. Repair of complete acromioclavicular separations using the acromioclavicular-hook plate. Clin Orthop Relat Res. 1995;314:134-142.

31. Tossy JD, Mead NC, Sigmond HM. Acromioclavicular separations: useful and practical classification for treatment. Clin Orthop Relat Res. 1963:28:111-119.

32. Walz L, Salzmann GM, Fabbro T, Eichhorn S, Imhoff AB. The anatomic reconstruction of acromioclavicular joint dislocations using 2 TightRope devices: a biomechanical study. Am J Sports Med. 2008;36(12):2398-2406.

33. Wellmann M, Kempka JP, Schanz S, et al. Coracoclavicular ligament reconstruction: biomechanical comparison of tendon graft repairs to a synthetic double bundle augmentation. Knee Surg Sports Traumatol Arthrosc. 2009;17(5):521-528.

34. Wellmann M, Lodde I, Schanz S, Zantop T, Raschke MJ, Petersen W. Biomechanical evaluation of an augmented coracoacromial ligament transfer for acromioclavicular joint instability. Arthroscopy. 2008; 24(12):1395-1401.

35. Wellmann M, Zantop T, Weimann A, Raschke MJ, Petersen W. Biomechanical evaluation of minimally invasive repairs for complete acromioclavicular joint dislocation. Am J Sports Med. 2007;35(6):955-961.

For reprints and permission queries, please visit SAGE's Web site at http://www.sagepub.com/journalsPermissions.nav 